\title{
Slant total electron content for Sirio-Mortelliccio ray path
}

\author{
Miguel A. Cabrera $\left({ }^{1}\right)\left({ }^{3}\right)$, Rodolfo G. Ezquer $\left({ }^{1}\right)\left({ }^{2}\right)\left({ }^{3}\right)$ and Paolo Spalla $\left({ }^{4}\right)$ \\ $\left.{ }^{(}\right)$Laboratorio de Ionósfera, Departamento de Física, Facultad de Ciencias Exactas y Tecnolgía, \\ Universidad Nacional de Tucumán, San Miguel de Tucumán, Argentina \\ ${ }^{(2)}$ Consejo Nacional de Investigaciones Científicas y Técnicas (CONICET), Buenos Aires, Argentina \\ $\left(^{3}\right)$ Facultad Regional Tucumán, Universidad Tecnológica Nacional, San Miguel de Tucumán, Argentina \\ $\left(^{4}\right)$ Istituto di Fisica dell'Atmosfera (IFA), CNR, Roma, Italy
}

\begin{abstract}
The Total Electron Content (TEC) is used to indicate the ionisation of the ionosphere. TEC is a quantity that concern for predicting space weather effects on telecommunications, improving the accuracy of satellite navigation, fly control vehicles and other systems that use transionospheric signals, because the ionospheric layer affects the mentioned signals. In this work the Slant Total Electron Content (STEC) was calculated with a technique that uses so-called «auxiliaries stations model», and a Chapman layer with scale height equal to atomic oxygen scale height (CHO). The validity was checked with STEC measurements obtained from geosynchronous satellite signals, for SIRIO-Mortelliccio link considering solstices and equinox, in high solar activity period. In general, the deviations between predictions and measurements were lower than $30 \%$ for $16 \mathrm{~h}$ per day (average). The results suggest that additional studies for other links and solar activity are required in order to improve the model predictions.
\end{abstract}

Key words Total Electron Content - ionosphere space weather - satellite - scale height

\section{Introduction}

For satellite and aircraft navigation systems or satellite orbit and position determination it is necessary to use radio signals transmitted between the satellite and the ground station (Harris et al, 2001; among others). The ionosphere produces several effects on transionospheric radio waves (Hargreaves, 1992). These effects are proportional to the number of free electrons en-

Mailing address: Dr. Miguel A. Cabrera, Laboratorio de Ionósfera, Departamento de Física, Facultad de Ciencias Exactas y Tecnolgía, Universidad Nacional de Tucumán, Av. Independencia 1800, 4000 San Miguel de Tucumán, Argentina; e-mail: mcabrera@herrera.unt.edu.ar countered by the wave on its passage through the ionosphere (total electron content, TEC) (Rishbeth and Garriot, 1969). TEC is a key parameter that describes the major impact of the ionized atmosphere on the propagation of radio waves, which is crucial for terrestrial and Earthspace communications. The ionospheric corrections that have to be applied to determine the position accurately are proportional TEC along the radar-satellite path (Hartmann and Leitinger, 1984; Lin, 2001; among others). So, for ionospheric corrections, TEC measurements are required, or TEC predictions from ionospheric models can be a useful tool.

Different ionospheric models have been developed to predict the electron density $(N)$ distribution in height, which is called $N$-profile (Chiu, 1975; Anderson et al, 1987; among others), including the IRI model (Bilitza, 1990; Rawer and Bilitza, 1990). With this $N$-profile the vertical total electron content can be obtained. Nevertheless, most of the signal paths are slant paths. 
In general to model the ionosphere, the socalled thin layer approximation is adopted (Manucci et al, 1999; among others), the STEC is related with the vertical total electron content (VTEC) through the piercing point with the obliquity factor (Ciraolo and Spalla, 2002; Brunini et al., 2004; among others).

The purpose of the present work is to calculate the TEC along the ground station-satellite ray path, called Slant Total Electron Content (STEC). A computation method and ionospheric model are used. We adopted a Chapman layer (Chapman, 1931) with scale height equal to atomic oxygen scale height, hereafter referred to as $\mathrm{CHO}$.

\section{Method}

To calculate the STEC the length of the slant path is divided into segments of $20 \mathrm{~km}$. The verticals that pass through the ends of these segments intersect the Earth's surface in different points that we call «auxiliaries stations». The coordinates of these stations are determined. With an ionospheric model the electron densities at the points where the slant path intersects the verticals of the auxiliaries stations are calculated and from them the slant $N$-profile is obtained. Then, a numerical integration method and this slant $N$-profile are used to calculated STEC up to $2000 \mathrm{~km}$ of altitude (Cabrera, 2003).

\section{Model and discussion}

The Chapman layer offers a simple way to explain the vertical structure of plasma in upper atmosphere (Yonezawa, 1955; Yonezawa and Takahashi, 1960; Titheridge, 1993; Huang and Reisnich, 2001). The Chiu (1975) empirical model assumes that, $F 2$ region plasma density can be expressed by two standard Chapman profile expressions, one for the bottomside of the $F$ layer and one for the topside. The semiempirical low-latitude ionospheric model (SLIM) (Anderson et al., 1987) assumes two modified Chapman expressions to obtain the $F$ region $N$ profile, one for the bottomside and one for the topside.
Wright (1960) has shown that is possible to apply the following Chapman expression to the $F$ region:

$$
N(z)=N m \exp \{0.5[1-z-\exp (-z)]\}
$$

where $z=(h-h m) / H$ is the normalised height measured from $\mathrm{hm}$ in units of the scale height $H$. He purposed to take $H$ as the scale height of atomic oxygen. In this paper we assume the Chapman expression given by eq. (3.1) with $H$ equal to atomic oxygen scale height. $\mathrm{Nm}$ and $\mathrm{hm}$ correspond to peak characteristics and are obtained from CCIR global maps (CCIR, 1982). $H$ was calculated using $H=k T / m g$, where $k, T, m$ and $g$ are Boltzman's constant, neutral temperature, atomic oxygen mass and the acceleration due to gravity, respectively. The value of $T$ is obtained from MSIS-86 model (Hedin, 1987).

The model predictions were compared with measurements obtained at Mortelliccio, a middle latitude station. Figure 1 shows the calculated STEC for SIRIO-Mortelliccio $\left(42.9^{\circ} \mathrm{N}\right.$, $10.7^{\circ} \mathrm{E}$ ) ray path. For the considered link the satellite was placed at $\left(0^{\circ} \mathrm{N}, 345^{\circ} \mathrm{E}\right)$. Equinoxes and solstices for high solar activity period are considered.

It can be seen that, in general, there is a good agreement between $\mathrm{CHO}$ model and measurements for solstices (June and December), $16 \mathrm{~h}$ per day (average). In December the model overestimates STEC during $14 \mathrm{~h}$. April picture shows a secondary maximum, at 19 UT, that the model does not describe. The fact that the modelled STEC values corresponding to winter are grater than those of summer shows that the model predicts the occurrence of the "winter anomaly» (Rishbeth and Garriot, 1969). The worst disagreement is observed for August, the model overestimates the measurements since 0 to 5 UT and 20 to $23 \mathrm{UT}$, with deviations greater than $30 \%$. In general the model represents the STEC with good agreement for hours of high ionisation, for the considered period.

Table I shows the deviations $(D)$ between modelled values and measurements. The white, light grey and dark grey boxes correspond to the cases where $D \leq 30 \%, 30<D \leq 50 \%$ and $D>50 \%$, respectively. It can be seen that for 

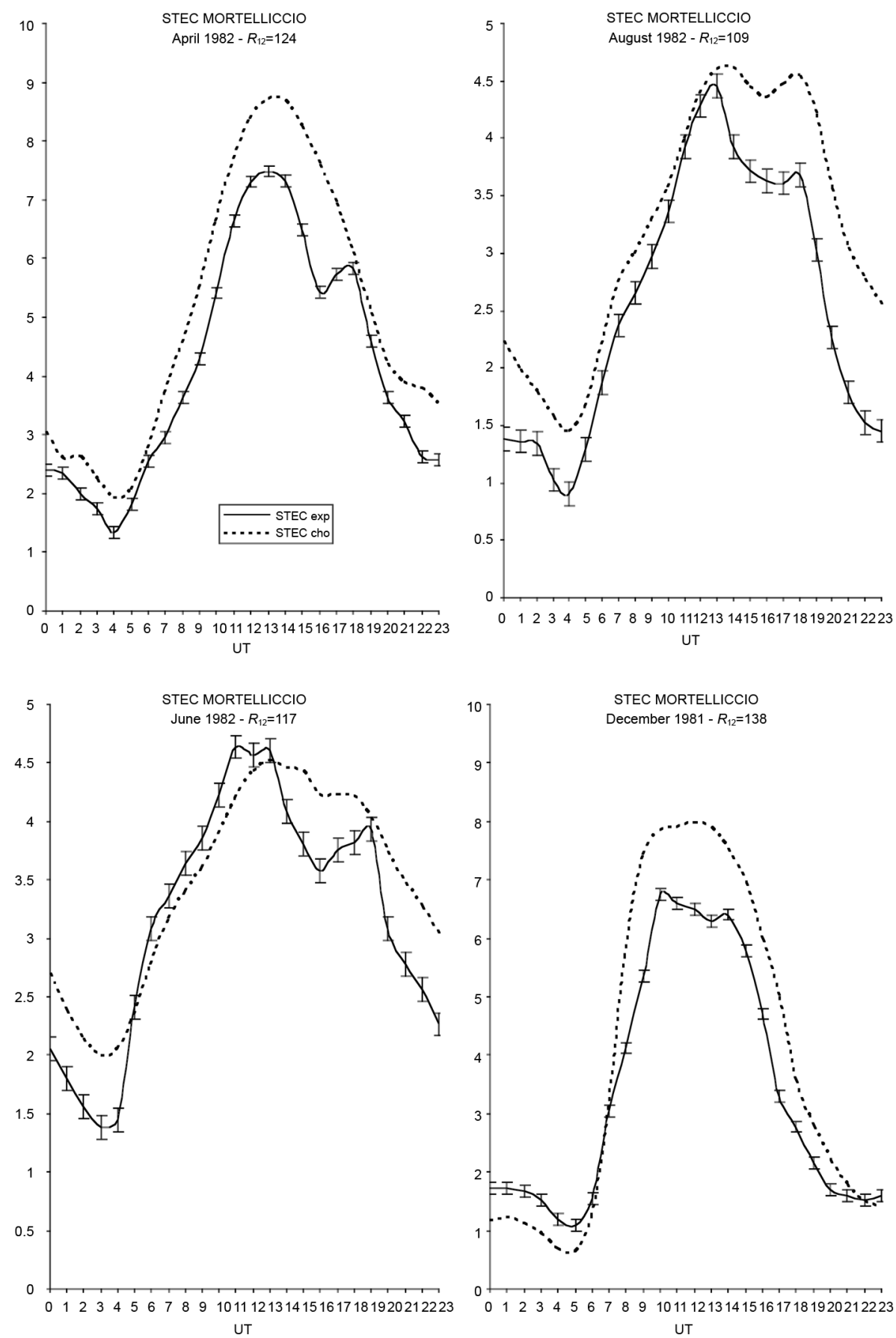

Fig. 1. Calculated and measured STEC for Mortelliccio-Sirio ray path: median values. 
Table I. Percentual deviations between modelled and measured values.

\begin{tabular}{ccccc}
\hline \hline CHO & \multicolumn{4}{c}{ Mortelliccio } \\
Date & April-82 & June-82 & August-82 & December-81 \\
$R_{12}$ & 124 & 117 & 109 & 138 \\
\hline 0 UT & 35.8 & 34.2 & 76.4 & 12.7 \\
1 & 27.1 & 31.5 & 61.5 & 31.9 \\
2 & 10.9 & 32.4 & 46.0 & 28.9 \\
3 & 31.5 & 38.0 & 33.1 & 33.4 \\
4 & 29.1 & 44.1 & 52.9 & 39.1 \\
5 & 43.9 & 41.9 & 60.6 & 42.8 \\
6 & 14.1 & 2.4 & 29.2 & 41.8 \\
7 & 9.5 & 9.7 & 17.8 & 19.7 \\
8 & 25.5 & 5.7 & 15.9 & 1.2 \\
9 & 25.9 & 6.8 & 13.0 & 38.0 \\
10 & 28.6 & 6.4 & 10.6 & 39.2 \\
11 & 22.8 & 8.0 & 6.5 & 16.4 \\
12 & 16.2 & 9.4 & 1.8 & 19.5 \\
13 & 14.8 & 3.0 & 2.5 & 22.8 \\
14 & 16.5 & 1.8 & 3.1 & 25.4 \\
15 & 18.6 & 9.1 & 17.3 & 17.8 \\
16 & 27.0 & 16.4 & 19.7 & 20.3 \\
17 & 39.9 & 18.3 & 20.2 & 27.2 \\
18 & 21.0 & 12.7 & 23.8 & 51.9 \\
19 & 4.9 & 10.1 & 23.6 & 28.8 \\
20 & 10.2 & 2.8 & 39.1 & 28.7 \\
21 & 16.3 & 21.8 & 57.6 & 30.6 \\
22 & 20.8 & 25.2 & 70.6 & 12.4 \\
23 & 44.7 & 27.4 & 82.6 & 0.8 \\
\hline & & & & \\
\hline
\end{tabular}

daytime hours a great amount of white boxes are observed. Few cases show deviations greater than $50 \%$ and they correspond to night time hours.

\section{Conclusions}

This work calculated the Slant Total Electron Content (STEC). A Chapman layer with scale height equal to atomic oxygen scale height $(\mathrm{CHO})$ was considered.

The validity was checked with STEC measurements obtained from geosynchronous SIRIO satellite signals and received at Mortelliccio, considering solstices and equinox, in high solar activity period.

For the considered cases, the results suggest that $\mathrm{CHO}$ model shows an adequate performance to predict the STEC. In general the deviations between predictions and measurements were lower than $30 \%$, for $16 \mathrm{~h}$ per day.

The observed disagreements between predictions and measurements could arise because peak characteristics or the shape of $N$ profile, or both are not well predicted.

Additional studies for other links and conditions are required in order to study the performance of the model to predict STEC.

\section{REFERENCES}

Anderson, D.N., M. Mendillo and B. Herniter (1987): A semi-empirical, low-latitude ionospheric model, $R e$ port AFGL-TR-85-0254 (Air Force Geophysics Laboratory, Hanscom AFB, Massachusetts).

BILITZA, D. (1990): International reference ionosphere, NSSDC/WDC-A-R\&S 90-22 (Maryland, EEUU).

Brunini, C., A. Meza, F. AzPilicuata, M.A. Van Zele, M. GENDE and A. DÍAZ (2004): A new ionosphere monitoring technology based on GPS, Astrophys. Space Sci., 290, 415-429.

CABrera, M.A. (2003): Ph.D. Thesis (Universidad Nacional de Tucumán, Argentina).

CCIR (1982): Comité Consultatif International des Radiocommunications (International Telecomunication Union, Place des Nations, Switzerland).

CHIU, Y.T. (1975): A improved phenomenological model of ionosphere density, J. Atmos. Terr. Phys., 37, 1536.

Ciraolo, L. and P. SPAlla (2002): TEC time variability, in Proceedings of the IRI Task Force Activity 2001, IC/IR/2002/23, Trieste.

HARGREAVES, J.K. (Editor) (1992): The Solar-Terrestrial Environment (Cambridge Atmospheric and Space Science Series, Cambridge University Press), pp. 420.

Harris, I.L., A.J. ManNUCCI, B.A. IIJIMA, U.J. LindQwisTER, D. MunA, X. PI and B.D. Wilson (2001): Ionospheric specification algorithms for precise GPS-based aircraft navigation, Radio Sci., 36 (2), 287-298.

Hartmann, G.K. and R. Leitinger (1984): Range error due to ionospheric and tropospheric effects for signals frecuencies above $100 \mathrm{MHz}$, Bull. Geodin., 58, 109-136.

HEDIN, A.E. (1987): MSIS-86 thermosphere model, J. Geophysics Res., 92, 4649.

HuAng, X. and B. Reinisch (2001): Vertical electron content from ionograms in real time, Radio Sci., 36 (2), 335-342.

LIN, LAO-SHENG (2001): Remote sensing of ionosphere using GPS measurements, in Proceedings Asian Assosiation on Remote Sensing, Singapore, vol. 1, 69-74.

Manucci, A.J., B.A. IiJima, U.J. Lindqwister, X. Pi, L. 
SPARKS and B.D. WILSON (1999): GPS and Ionosphere, Revised Submission to URSI Reviews of Radio Science (Jet Propulsion Laboratory, Pasadena, CA).

RAWER, K. and D. BILITZA (1990): International reference ionosphere-plasma densities: status 1988, Adv. Space res., $10(8)$, 5-14.

Rishbeth, H. and O.K. GARRIOT (1969): An Introduction to Ionospheric Physics (Academic Press, New York and London), pp. 331.

Titheridge, J.E. (1993): Atmospheric winds calculated from diurnal changes in the mid-latitude ionosphere, $J$. Atmos. Terr. Phys., 55, 1637-1659.
Wright, J.W. (1960): A model of de $F$ region above $h_{\max } F 2$, J. Geophys. Res., 65 (1), 185-191.

YonEZAWA, T. (1955): On influence of the electron-ion diffusion on the electron density and height of the nocturnal F2 layer, J. Radio Res. Lab., 2 (8), 125-136.

YonEZAWA, T. and H. TAKAHASHI (1960): On the electron and ion density distributions from the lower uppermost part of the F region, J. Radio Res. Lab., 7 (32), p. 335.

(received September 15, 2005; accepted July 27, 2006) 